\title{
Investigation of the Influence of Strategy Orientation Dimensions on Performance of Companies which are Active in Food Industries in Alborz Province
}

\section{Zahra Ghorbaninia}

Department of Business Management, Qazvin Branch, Islamic Azad University, Qazvin, Iran

Mansoureh Aligholi*

\begin{abstract}
Department of Business Management, Faculty of Management, Central Tehran Branch, Islamic Azad University, Tehran, Iran
\end{abstract} *Corresponding Author: Email: man.aligholi@iauctb.ac.ir

\author{
Doi:10.5901/mjss.2016.v7n2s1p503
}

\begin{abstract}
The present research aims to investigate the influence of dimensions of strategy orientation of organizational performance in companies which are active in food industries in Alborz province. This study is an applied research in terms of target and it is a descriptive study in terms of data gathering method and it is a correlation study in terms of data analysis. Research statistical population included all companies which were active in food industries in Alborz Province (152 companies in number). According to Morgan Table, 108 companies were selected randomly. Questionnaire was used for data gathering. Regression coefficient method was used for testing hypotheses. The results of analyses showed that except for risk taking, all other dimensions of strategy orientation (aggressive approach, defensive approach, analytical approach, futurism and proactiveness) had positive impacts on organizational performance.
\end{abstract}

Keywords: organizational performance, strategy orientation, companies active in food industries, Alborz Province

\section{Introduction}

In any organization, either production or service, customers are the most important factor in organizational conservation and if an organization is not able to attract satisfaction and loyalty, it will damage its long-term growth (Tavanazadeh \& Aligholi, 2014). Today, business environment is very volatile (O'regan\&Ghobadian, 2005). Moreover, business environment has become very competitive as a result of technology advancements, globalization, and international activities of multinational organizations. In such conditions, strategy oriented organizationswhich care about their weak points/strengths and threats/opportunities in the market can have better performance. An investigation of research literature reveals that strategy orientation has positive impacts on innovation, competitiveness and organizational performance (Kumar et al, 2012). In fact, strategy orientation involves models for responding to an environment in order to increase performance and competitive advantage (Hambrick, 1983). In any organization, either a production or a service one, the main factor for organizational survival is customers. If an organization fails to attract their loyalty, it will not guarantee its long-term survival (Vazifehdoost, Rahnama and Mousaviyan, 2014).For decades, a company's value was measured based on its equipment, properties, tangible assets and factories. However, it is now believed that the real value of a company is somewhere in potential consumers' minds (Heidarzadeh et al, 2011). Hakala (2011) defines strategy orientation as factors which influence organizational activities and direct them. Therefore, it seems that identification of dimensions of strategy orientation and their impacts on business performance can have good results for managers considering the importance of strategic management in different organizational performances like innovation, acquisition of competitive advantage, competitiveness and so on. Food industry is an industry which is very fiercely competitive. Considering the fact that customers have many different options under competitive conditions, absence of a strategic view towards market, competitors and customers can result in reduction of profitability and elimination of the organization from market. Therefore, in the present research we try to investigate relationships between organizational strategy orientation dimensions and organizational performance. The main subject of this study is to examine the existing status of strategy orientation in businesses active in food industry and to investigate the potential influence of dimensions of strategy orientation on performance of organizations which are active in food industries. 


\section{Strategy Orientation}

Strategy orientation involves a philosophy which directs business movement and has its roots deeply in values and beliefs which are infrastructures for organizational activities and attempts for directing competitive advantage (Zhou et al, 2005; Johnson et al, 2012). Strategy orientation is reflected in appropriate organizational activities which result in supreme performance (Slater et al, 2006). Strategy orientation refers to decision-making styles, processes and activities which determine business orientation in relation to surroundings. This interaction can be reflected in the form of establishment of new businesses, entering international markets or formation of organizational strategies. An investigation of research literature strategy orientation has positive impacts on innovation, competitiveness and organizational performance (Kumar et al, 2012). In fact, strategy orientation involves models for responding to an environment in order to increase performance and competitive advantage (Hambrick, 1983). Hakala (2011) defines strategy orientation as factors which influence organizational activities and direct them (Hakala, 2011). Venkatraman approach was used in this research for investigation of strategy orientation. He considered 6 dimensions for strategy orientation: aggressive, defensive, futurism, proactiveness, analytical and risk taking. "According to Porter Diamond Model (Porter, 1990), firm strategy orientation is an important driver of competitiveness. Various studies have confirmed that strategy orientation of organizations can enhance their competitiveness in their businesses (Porter, 1991; Riasi, 2015; Riasi \& Pourmiri, 2015). Studies on Iranian firms have also confirmed this relationship (Amiri Aghdaie et al., 2012; Porter, 1990; Riasi \& Amiri Aghdaie, 2013), which further magnifies the importance of the concept of strategy orientation."

\subsection{Defensive Dimension}

Defensive approach refers to behaviors which are aimed at reducing costs and finding methods for increasing efficiency (Venkatraman, 1989). Defensive organizations are those which have limited market-product domain and are concentrated on improvement of processes and efficiency. Managers of these organizations are strong experts in managing their tasks but they do not tend to search for their working domain in order to acquire new opportunities (Miles and Snow, 1978). Defensive organizations have been able to maintain their limited position in industries which are difficult to penetrate for other competitors.

\subsection{Futurism}

Future orientation refers to a company's viewpoint towards future. This means that future is more important than present and concentration on long-term plans is more important than short-term benefits (Venkatraman, 1989). Futurists are those organizations which are persistently looking for new opportunities in markets. they create changes and uncertainties and challenge their competitors. They actually tend to lead changes (Morgan and Strong, 1998). Moreover, a futurist company may have fewer tendencies to severe competition in the short term. Moreover, a company with short term orientation may act via immediate response mechanisms in order to compete other companies (Morgan and Strong, 2003).

\subsection{Aggressive Dimension}

Aggressive approach involves use of resources for improvement of market situation. This dimension of strategy orientation requires a lot of investment and emphasizes on development of market share (Morgan and Strong, 2003). A company is aggressive when it uses its resources to excel competitors and looks for market share increase in order to win competition (Venkatraman, 1989; Morgan and Strong, 2003) and tends to have a strong challenge with competitors for acquiring efficiency (Ferrier, 2001).

\subsection{Proactiveness Dimension}

This dimension emphasizes on being one step ahead of other competitors. Proactiveness is concentrated on innovative behaviors and tries to find new products and markets. Companies with this competitive behavior have market leadership features (Morgan and Strong, 2003). Proactive approach indicates a company's eagerness for seizure of emerging opportunities and necessary actions to cope with changes and threats (Dess et al, 1997). Proactive companies try to improve business in order to guarantee high efficiency and such a company is expected to have a considerable growth (Day and Wenshley, 1988). 


\subsection{Risk Taking Dimension}

Risk taking refers to a company's tendency to take risks in strategic activities and approaches (Venkatraman, 1989). Risk taking is important in resource allocation and is a key parameter in determination of decision making processes in competitive strategy. Risk taking is more an intuitive feature than being an analytical one and requires considerable human resource and financial investment. Risk taking indicates uncertainty about acquisition of positive potential results or potential destructive results from decisions and activities (Morgan and Strong, 2003).

\subsection{Analytical Dimension}

Analytical organizations are those which are active in two types of market-product area. One is constant conditions and the other is changing conditions. In stable and constant conditions, these organizations are active routinely and efficiently via structure and standard processes. In volatile and changing conditions, however, senior managers monitor their competitors and try to become compatible with new successful ideas (Miles and Snow, 1978). Analytical dimension provides general problem-solving approach to strategic decisions which result in a thorough understanding of environmental and organizational issues. This dimensionreflects organizational knowledge for empowering and facilitating organizational learning processes (Miller and Freisen, 1983).

\section{Organizational Performance}

In any organization, whether production or service, customers are the most important factor in organizational conservation and if an organization is not able to attract satisfaction and loyalty, it will damage its long-term growth (Rahnama et al, 2012). As competition increases in production and services, organizations have found models and indices for measurement and evaluation of their performances (Valmohammadi and Firouzeh, 2010).

In most organizations, organizational managers and leaders try to improve their performances. Organizational performance is a complete combination of intangible inputs like organizational knowledge and tangible inputs like economic and financial results (Allameh and Moghaddami, 2010). Traditionally, financial approach is used for performance evaluation. Today, this approach is no longer useful for performance evaluation because financial indices were complimentary to machine-like nature of past organizations (Niven, 2002). Kaplan and Norton revealed much inefficiency of financial indices for evaluation of performance after evaluation of management accounting systems. These inefficiencies were resulted from increase in organizational complexities, environmental dynamism and market competition (Kaplan and Norton, 1992).

Within the past few years, high level of service quality provided for customers has been considered as an instrument to reach competitive advantages. In order to have a long-term relationship with customers, banks must know how they can provide high-quality services. In customers' strategy, customer's loyalty is of strategic importance for any organization. Increase in customers' loyalty is a common subject among university managers and advisors(Haghighi et al, 2012).

\section{Research Conceptual Model}

Considering research literature and research goal-which is to investigate the influence of dimensions of strategy orientation on organizational performance-, we used the conceptual model in figure 1 for investigation of the influence of strategy orientation on organizational performance in food industry in Alborz Province. 


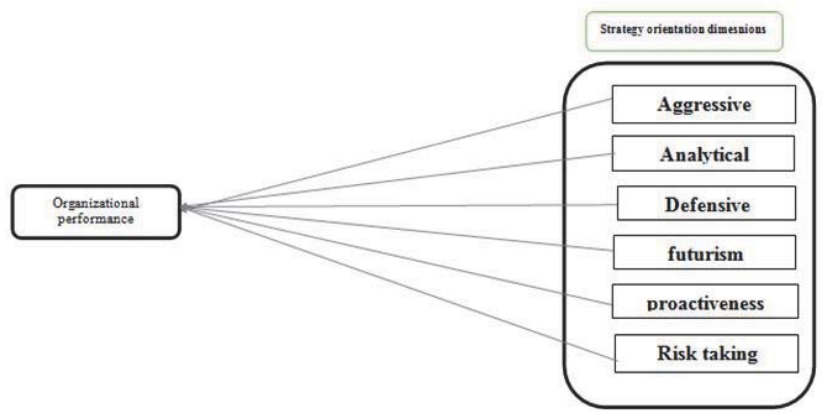

Figure 1. Research conceptual model

Source: Morgan \& Strong, 2003; Johnson et al., 2012

According to research conceptual model, research hypotheses are as follows:

$\mathrm{H1}$ : aggressive approach has a positive influence on performance of companies which are active in food industry in Alborz Province.

$\mathrm{H} 2$ : analytical approach has a positive influence on performance of companies which are active in food industry in Alborz Province.

H3: defensive approach has a positive influence on performance of companies which are active in food industry in Alborz Province.

H4: futurism approach has a positive influence on performance of companies which are active in food industry in Alborz Province.

H5: proactiveness approach has a positive influence on performance of companies which are active in food industry in Alborz Province.

H6: risk taking approach has a positive influence on performance of companies which are active in food industry in Alborz Province.

\section{Research Methodology}

The present research is an applied study in terms of goal. In terms of data gathering, it is a descriptive study. Furthermore, it is a correlation study in terms of data analysis. Analysis was conducted by means of structural equations modeling technique.

Data gathering instrument

Questionnaire was used for data gathering. Five-point Likert scale was used as measurment scale, answers ranging from "completely disagree" to "completely agree". After preparation of questionnaire, 25 questionnaires were distributed among respondents in order to investigate reliability of questionnaire. Cronbach's alpha was used for investigation of reliability. The results showed that Cronbach's alpha was equal to 0.7 and above that (Cronbach's alpha coefficients have been listed in table 2). Moreover, content validity of the questionnaire was also verified by experts and professors. Therefore, the questionnaire has enough validity and reliability for being distributed among sample members.

Table 2. Cronbach's alpha coefficients

\begin{tabular}{|c|c|c|c|c|}
\hline Research variables & Dimensions & Questions & Cronbach's alpha & Source of questions \\
\hline \multirow{6}{*}{ 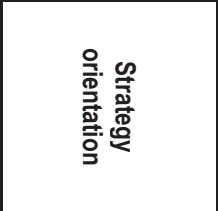 } & Aggressive & $1-4$ & \begin{tabular}{|l|}
0.797 \\
\end{tabular} & \multirow{6}{*}{ Morgan \& Strong, 2003; Johnson et al., 2012} \\
\hline & Analytical & $5-8$ & 0.709 & \\
\hline & defensive & $9-12$ & 0.761 & \\
\hline & futurism & $13-16$ & 0.886 & \\
\hline & proactiveness & $17-20$ & 0.726 & \\
\hline & Risk taking & $21-24$ & 0.884 & \\
\hline performance & - & $25-30$ & 0.824 & Avci et al, 2011; Morgan \& Strong, 2003 \\
\hline total & - & $1-30$ & 0.90 & \\
\hline
\end{tabular}




\section{Statistical Population and Sample}

Statistical population of the research included all companies which were active in the field of food industry in Alborz Province. Because population is limited and we do not have any information about variance of the population, we used Morgan Table in which sample sizes have been estimated conservatively (in large values). Considering population size (152 companies), sample size was estimated to be equal to 108. Demographic information of the respondentshave been presented in table 3.

Table 3. Demographic information of respondents

\begin{tabular}{|l|c|c|c|c|}
\hline Variable & Dimensions & Frequency & Frequency percentage & Cumulative percentage \\
\hline \multirow{4}{*}{ Number of employees } & Below 30 & 28 & 25.9 & 25.9 \\
\cline { 2 - 5 } & $\mathbf{3 1 - 5 0}$ & 45 & 41.7 & 67.6 \\
\cline { 2 - 5 } & $\mathbf{5 1 - 1 0 0}$ & 31 & 28.7 & 96.3 \\
\cline { 2 - 5 } & More than 100 & 4 & 3.7 & 100.0 \\
\hline \multirow{4}{*}{ Activity time } & Below 5 & 8 & 7.4 & 7.4 \\
\cline { 2 - 5 } & $\mathbf{6 - 1 0}$ & 32 & 29.6 & 37.0 \\
\cline { 2 - 5 } & $\mathbf{1 1 - 2 0}$ & 46 & 42.6 & 79.6 \\
\cline { 2 - 5 } & More than 20 & 22 & 20.4 & 100.0 \\
\hline
\end{tabular}

\section{Data Analysis and Hypotheses Test}

We used regression analysis for investigation of the influence of strategy orientation dimensions on organizational performance. The results of regression analysis have been presented in table 4 .

Table 4. Regression analysis results

\begin{tabular}{|l|c|c|l|}
\hline Cumulative percentage & Standard beta coefficient & significance & Hypothesis result \\
\hline Aggressive---organizational performance & .437 & 0.000 & Hypothesis supported \\
\hline Analytical---organizational performance & .491 & 0.000 & Hypothesis supported \\
\hline Defensive---organizational performance & .602 & 0.000 & Hypothesis supported \\
\hline Futurism---organizational performance & .563 & 0.000 & Hypothesis supported \\
\hline Proactiveness----organizational performance & .629 & 0.000 & Hypothesis supported \\
\hline Risk taking---organizational performance & .061 & .360 & Hypothesis rejected \\
\hline
\end{tabular}

Considering the results of regression analysis, we investigate research hypotheses in the subsequent sentences:

H1: Aggressive approach has a positive influence on performance of companies which are active in food industry in Alborz Province.

Considering the results summarized in table 4, standard beta coefficient for aggressive approach is positive and equal to 0.437 . Since significance probability (Sig) is smaller than 0.05 , it is significant in 0.95 . Therefore, the first hypothesis of the research is accepted. This means aggressive approach has a positive impact on performance of companies which are active in food industry in Alborz Province.

$\mathrm{H} 2$ : Analytical approach has a positive influence on performance of companies which are active in food industry in Alborz Province.

Considering the results summarized in table 4, standard beta coefficient for analytical approach is positive and equal to 0.491 . Since significance probability (Sig) is smaller than 0.05 , it is significant in 0.95 . Therefore, the second hypothesis of the research is accepted. This means analytical approach has a positive impact on performance of companies which are active in food industry in Alborz Province.

H3: Defensive approach has a positive influence on performance of companies which are active in food industry in Alborz Province.

Considering the results summarized in table 4, standard beta coefficient for defensive approach is positive and equal to 0.602 . Since significance probability ( $\mathrm{Sig})$ is smaller than 0.05 , it is significant in 0.95 . Therefore, the third hypothesis of the research is accepted. This means defensive approach has a positive impact on performance of companies which are active in food industry in Alborz Province.

H4: Futurism approach has a positive influence on performance of companies which are active in food industry in 


\section{Alborz Province.}

Considering the results summarized in table 4, standard beta coefficient for futurism approach is positive and equal to 0.563 . Since significance probability ( $\mathrm{Sig}$ ) is smaller than 0.05 , it is significant in 0.95 . Therefore, the fourth hypothesis of the research is accepted. This means futurism approach has a positive impact on performance of companies which are active in food industry in Alborz Province.

H5: Proactiveness approach has a positive influence on performance of companies which are active in food industry in Alborz Province.

Considering the results summarized in table 4 , standard beta coefficient for proactiveness approach is positive and equal to 0.629 . Since significance probability (Sig) is smaller than 0.05 , it is significant in 0.95 . Therefore, the fifth hypothesis of the research is accepted. This means proactiveness approach has a positive impact on performance of companies which are active in food industry in Alborz Province.

H6: Risk taking approach has a positive influence on performance of companies which are active in food industry in Alborz Province.

Considering the results summarized in table 4 , because significance probability for regression coefficient is greater than 0.05 , risk taking does not have any influence on performance of companies active in food industry in Alborz Province. In other words, the influence of risk taking on performance of companies active in food industry in ALborz Province was not supported.

\section{Conclusion and Discussion}

The present research aimed to investigate the influence of strategy orientation dimensions on organizational performance in food industry in Alborz Province in Iran. Venkatraman (1989) approach was used for investigation of strategy orientation. He considered 6 dimensions: aggressive, analytical, defensive, futurism, proactiveness, risk taking as dimensions of strategy orientation. Regression analysis test was used for measurement of the influence of these dimensions on organizational performance. The results showed that aggressive, analytical, defensive, futurism and proactiveness dimensions had positive and significant impacts on organizational performance but the impact of risk taking on organizational performance was not significant. Furthermore, investigations showed that proactiveness dimension (beta $=0.629$ ) had the greatest impact and aggressive dimension (beta=0.437) had the smallest impact on organizational performance. The results of data analyses and hypotheses test showed that all dimensions of strategy orientation had significant impacts on organizational performance but risk taking. Furthermore, of five dimensions, proactiveness had the greatest impact on organizational performance and aggressive approach had the smallest impact on organizational performance. Therefore, the following recommendations are presented for improvement of organizations active in food industry:

The following recommendations are presented for improvement of organizational performance in food industry companies:

1. In general, if we want to implement strategies for companies, we should consider strategic group . market competitors are divided into four groups: market leader, market challengers, market followers and market niche. Each position requires some particular strategies. Analysis of research data revealed that aggressive approach influences organizational performance. Of course, this dimension has the smallest influence on organizational performance. Strategies like price war, widespread advertisements, presentation of similar products with higher quality and more innovation, ignorance of short-term profits in favor of long-term success. Furthermore, companies which are market challengers are also recommended to follow aforementioned strategies.

2. An analysis of research data revealed that analytical approach influences organizational performance. Regarding this result, organizations are advised to analyze their situation carefully before making decisions and do operational and strategic planning considering their conditions. Furthermore, they should get equipped with information systems which facilitate optimal use of information.

3. Analysis of research data revealed that defensive approach influences organizational performance. Having growing and aggressive strategies may not result in improvement of organizational performance in all cases but defensive strategies may yield better fruits. Regarding this result, organizations should concentrate on maintaining their existing optimal status and should use operational and strategic plans and control costs in order to increase productivity. Furthermore, by analyzingcompetitive strategies and identification of their actions, they should keep their current market share and existing situation.

4. Analysis of research data revealed that futurism approach influences organizational performance. Prediction of 
future and future events has been always liked by human and organizations because prediction is a preamble to planning. Regarding this result, management should make use of instruments like scenario analysis, analysis of key industry indices, analysis of time series, use of experts ideas, econometric techniques and ... in order to predict their own and their competitors' trends and also social, economic, political and economic trends as players of macro environment in order to influence organizational performance.

5. Analysis of research data revealed that proactiveness influences organizational performance. This approach emphasizes on being one step ahead of competitors. Therefore, it is recommended that organizations identify customers' needs and expectations (even needs customers are not aware of) before competitors and present new processes and products and innovative activities. Furthermore, management of organizations should update information of their own industry and use newly born technologies instead of outdated technologies.

6. Considering research results, risk taking does not have any significant influence on organizational performance. This result is not consistent with the results of previous studies. This may be attributed to the environment of competition because about $90 \%$ of Iranian companies compete inside borders and indices of internal group and strategic group do not allow for continuing strategies with high risk.

\section{References}

Allameh, Seyyed Mohsen and Moghaddami, Mehdi (2010). An investigation of relationship between organizational learning and organizational performance; case study: Iran Khodrodriving force unit, journal of scientific-research executive management, year 10, number 1: 75-99.

Altuntaş, G., Semerciöz, F., \&Eregez, H. (2013). Linking strategic and market orientations to organizational performance: the role of innovation in private healthcare organizations. Procedia-Social and Behavioral Sciences, 99, 413-419.

Amiri Aghdaie, S. F., Seidi, M., \& Riasi, A. (2012). Identifying the Barriers to Iran's Saffron Export by Using Porter's Diamond Model. International Journal of Marketing Studies, 4(5), 129-138.

Chandra B. K. (2014). Strategic orientation and organizational forms: an integrative framework. European Business Review, 26(2), 188203.

Day, G. S., \&Wensley, R. (1988).Assessing advantage: a framework for diagnosing competitive superiority. The Journal of Marketing, 120.

Dess G, Lumpkin GT, Covin JG. (1997), Entrepreneurial strategy making and firm performance: tests of contingency and configurational models. Strategic Management Journal, 18:677-695.

Ferrier, W. J. (2001).Navigating the competitive landscape: The drivers and consequences of competitive aggressiveness. Academy of Management Journal, 44(4), 858-877.

Gatignon, H., \&Xuereb, J. M. (1997).Strategic orientation of the firm and new product performance.Journal of marketing research, 77-90.

Haghighi, Mohammad; Dorosti, Ali; Rahnama, Afshin; Hoseinpour, Ali;(2012) 'Evaluation offactors affecting customer loyalty inthe restaurant industry' African Journal of Business Management Vol. 6(14), pp. 5039-5046

Hakala, H. (2011). Strategic orientations in management literature: three approaches to understanding the interaction between market, technology, entrepreneurial and learning orientations. International Journal of Management Reviews, 13(2), 199-217.

Hambrick, D. C. (1983). Some tests of the effectiveness and functional attributes of Miles and Snow's strategic types. Academy of Management journal, 26(1), 5-26.

HeidarzadehHanzaee, Kambiz; Khoshpanjeh, Mahsa \&Rahnama, Afshin., (2011). "Evaluation of the effects of product involvement facets on brand loyalty" African Journal of Business Management Vol. 5(16), pp. 6964-6971.

Johnson, J. L., Martin, K. D., \&Saini, A. (2012). The role of a firm's strategic orientation dimensions in determining market orientation. Industrial Marketing Management, 41(4), 715-724.

Kaplan, R.S. and Norton, D.P. (1992), The Balanced scorecard: Measures that Drive performance, Harvard Business Review, JanuaryFebruary

Kumar, K., Boesso, G., Favotto, F., \&Menini, A. (2012).Strategic orientation, innovation patterns and performances of SMEs and large companies. Journal of Small Business and Enterprise Development, 19(1), 132-145.

Miles R.E, Snow C (1978). Organizational strategy, structure, and process. New York: McGraw-Hill

Miller, D., \& Friesen, P. H. (1983). Strategy-making and environment: the third link. Strategic management journal, 4(3), 221-235.

Morgan R, Strong C (2003). Business performance and dimensions of strategic orientation. Journal of Business Research, 56(3): 163176.

Morgan, R., Strong C (1998). Market orientation and dimensions of strategic orientation. European Journal of Marketing, 32(11/12): 1051-1073.

Niven, P. R. (2002). Balanced scorecard step-by-step: maximizing performance and maintaining results. John Wiley \& Sons.

O'Regan, N., \&Ghobadian, A. (2005). Innovation in SMEs: the impact of strategic orientation and environmental perceptions. International Journal of Productivity and Performance Management, 54(2), 81-97.

Porter, M. E. (1990). The Competitive Advantage of Nations. New York, NY: The Free ress.

Porter, M. E., \& the Monitor Company (1991). Canada at the crossroads: The reality of a new competitive environment.Ottawa: Business 
Council on National Issues and Minister of Supply and Services of the Government of Canada.

Rahnama, Afshin; Mousavian, Seyed Javad; Alaei, Abbas; Salimi Maghvan, Tavakkol;(2011)"The survey of relationship between creativity of staffs and organizational effectiveness" Australian Journal of Business and Management Research Vol.1 No.6 [97104].

Riasi, A. (2015). Competitive Advantages of Shadow Banking Industry: An Analysis Using Porter Diamond Model. Business Management and Strategy, 6(2), 15-27.

Riasi, A., \& Amiri Aghdaie, S. F. (2013). Effects of a Hypothetical Iranian Accession to the World Trade Organization on Iran's Flower Industry. Consilience: The Journal of Sustainable Development, 10(1), 99-110.

Riasi, A., \& Pourmiri, S. (2015). Effects of online marketing on Iranian ecotourism industry: Economic, sociological, and cultural aspects. Management Science Letters, 5(10), 915-926.

Slater, S. F., Olson, E. M., \&Hult, G. T. M. (2006).The moderating influence of strategic orientation on the strategy formation capabilityperformance relationship. Strategic Management Journal, 27(12), 1221-1231.

Tavanazadeh, Somayeh.,Aligholi, Mansoureh., (2014). "Investigation of Relationship between Service Quality Dimensions and Customers' Satisfaction (case study: Saderat Bank Branches in Tehran City, Iran)" Mediterranean Journal of Social Sciences, Vol 5 No 20, 3116-3120.

Theodosiou, M., Kehagias, J., \&Katsikea, E. (2012). Strategic orientations, marketing capabilities and firm performance: An empirical investigation in the context of frontline managers in service organizations. Industrial Marketing Management, 41(7), 1058-1070.

Valmohammadi, Chengiz; Firouzeh, Negin (2010).Evaluation of organizational performance using BSC (case study), management quarterly, seventh year, number 1: 72-87.

Vazifehdoost, Hossein.,Rahnama, Afshin., Mousavian, SeyedJavad., (2014). "Evaluation of the Impact of Brand Purchase Involvement, Satisfaction, Experience and Brand Trust on Loyalty to Brand" Mediterranean Journal of Social Sciences, Vol 5 No 20, 30543063.

Venkatraman N (1989). Strategic orientation of business enterprises: the construct, dimensionality, and measurement. Management Science; 35(8): 942-962.

Zhou, K. Z., Yim, C. K., \&Tse, D. K. (2005).The effects of strategic orientations on technology-and market-based breakthrough innovations. Journal of marketing, 69(2), 42-60. 